\title{
The Analysis of English-Persian Legal Translations Based on Systemic Functional Grammar Approach (SFG)
}

\author{
Ferdows Aghagolzadeh \\ Tarbiat Modares University, Tehran, Iran \\ Email: aghagolz@modares.ac.ir \\ Faezeh Farazandeh-pour \\ Tarbiat Modares University, Tehran, Iran \\ Email: f_farazandeh@yahoo.com
}

\begin{abstract}
This paper tries to analyze the errors arising in translation of legal documents from English to Persian. Most of the researchers conducted on explaining the complexity of legal language, has shown that vocabulary and terminology has justifiably received the most attention, as lexis fulfills the symbolic or representational function of language better than any other linguistic component. Consequently it has been supposed that in legal translation, just finding appropriate equivalent for vocabulary and terminology is sufficient. But in this paper, which examines the errors occurred in English -Persian translation of legal documents, the translated text will be analyzed at sentence level based on a meaning-based functional approach ; i.e. Systemic Functional Grammar Approach (SFG) to see whether we can apply it as an objective criteria for error analysis of translated legal documents \& how. For this purpose, nine error categories were considered; including interpersonal, textual, logical and experiential metafunctions and in order to understand experiential meaning, it was broken into three functional constituents; that is participant, process and circumstance. Further to the above categories, three other issues, including mistranslation, omission and word choice were considered, as well. Then while dividing the legal text into separate sentences, each sentence was analyzed according to these categories. The results of this research show that SFG approach would be an appropriate criteria and scale for evaluating the accuracy of the legal documents translation, not only for legal translators in producing an accurate and perfect translation, but also for teachers in evaluating the students' translation abilities, objectively.
\end{abstract}

Index Terms - legal translation, Systemic Functional Grammar (SFG), ideational metafunction, interpersonal metafunction, textual metafunction, experiential meaning, logical meaning

\section{INTRODUCTION}

The translation of law has played an important role in the contact between different cultures in history and it is playing a more important role in our globalized world with the ever-increasing demand for legal translation. It has been always acknowledged that legal translation is complex and that it requires special skills, knowledge and experience on the part of translator to produce such translation.

"Legal Translation" is a type of special or technical translation, a kind of translational activity that involves special language use, that is, Language for Special Purpose (LSP) in the context of law, or Language for Legal Purpose (LLP) (Cao, 2010). In other word, legal translation consists of taking a document in one language and switching it to another language whilst maintaining the same meaning. Legal translation deals with legal issues and terms. This field involves translating statutes, contracts, patents and any type of legal documentation. These documents are often used in legal proceedings where the initial original meaning must be maintained even after the translation.

Legal terminology is very complex and can vary from one country to another. Due to the fact that not every country has the same legal system, in some cases legal concepts do not have an equivalent in the target language; such as the difference between legal system of Iran and Britain. Britain is a common law country in which the system of justice depends heavily on custom and precedent. By contrast, Iran is a civil law country where the legal system is based entirely on a body of written law. Codes and laws have been created to suit a particular country or culture and when the legal term does not have an equivalent in the target language, the translator needs to "recreate" the concept and whole idea attached to the legal expression. It is very difficult to find equivalent between two terms if both legal languages refer to different legal systems. Vlachopoulos (2004) proposes a range of solutions including the use of terms which are close in conceptual context from non-legal registers including every- day language. Otherwise one is obliged to use extensive footnoting and discussion of the translation itself. 
So expert knowledge and acquaintance will linguistic conventions on law and legal cases are required when doing legal translation; but these are not sufficient and it is required to give explicit criteria for evaluating legal translations in order to be used as an objective tool for producing comprehensive translations.

Therefore, in this paper we try to apply SFG approach to evaluate English- Persian legal translations; since SFG provides a fundamental basis for a comprehensive understanding of meaning. The following section briefly introduces a few concepts of SFG and the history of translation studies in Iran.

\section{BASIC CONCEPTS}

SFG was initially devised by Michael Halliday in the 1950s and 1960s. Williams (1994) notes that it continues to be developed by Halliday and linguists such as Ruqaiya Hasan, Jim Martin and Christian Matthiessen. It has been applied to translation studies, and translation assessment in particular, by translation scholars such as House (1986); Baker (1992); Hatim and Mason (1990, 1997); and Trosborg (2002). Systemic Functional linguists regard language as a meaning-making resource through which people interact with each other in given situational and cultural contexts. They are mainly interested in how language is used to construe meaning. Therefore, language is understood in relation to its global as well as local contexts. In SFL, it is common practice to study lexico-grammar, which is mainly concerned with meaning at the text or discourse level, and vice versa. This is one of the reasons for the strong relevance of SFL theory to translation studies. Translators cannot produce a coherent text without working on meaning at the text level (Kim, 2010). Two basic notions of SFG are as follows: firstly, a distinctive meaning is construed through three simultaneous strands of meaning and, secondly, a clause is a unit in which these meanings are combined (Halliday 1994). The meanings are referred to in SFG as metafunctions, and three such metafunctions are identified: ideational (resources for construing our experience of the world as meaning); interpersonal (resources for enacting our social roles and relations as meaning); and textual (resources for presenting ideational and interpersonal meanings as a flow of information in text). The ideational metafunction is split into two: experiential (resources for organizing experience as meaning) and logical (resources for expressing certain general logical relations as meaning).

SFG makes use of two types of grammatical labels: names of classes, including terms such as verb, noun, adjective, adverb prepositional phrase, noun group, etc; and names of function, including participant, process, subject, predicator, theme, rheme, etc. A constituent that is a member of a single class can have multiple functions in a clause. SFG approach towards language is fundamentally different from traditional school grammar. Williams (1994) explains that the most important difference between SFG and traditional school grammar is the metaphor of choice: Whereas school grammars have prescribed the correct from, functional grammar views language as a resource-one which makes semantic choices available to speakers and writers.

\section{REVIEW OF LITERATURE}

Investigation of the previous studies shows that the translation studies and specially the analysis of translation errors for training professional translators have a relatively short history and in fact no researches have been done on the analysis of legal translation in Iran; even though translation as a human activity has a very long history. So this indicates the necessity of research in this regard. Here a brief summary of the most important papers and researches conducted on translation evaluation in Iran is given as follows:

- "A Framework for Translation Evaluation" by Khomeyjani Farahani A.A. (2005) that suggests a format that can be used to evaluate the English translation of Islamic texts and decide whether the translation under discussion meets the requirements of a successful translation or not. This format is practically a set of criteria, which can be used to systematically evaluate the translation of a text from a source language into a target language and establish its merits and demerits.

- “A Function- Based Approach to Translation Quality Assessment” by Manafi Ansari S. (2004) which is based on a function-based approach to translation quality assessment. In this approach, the original text is sometimes regarded as a mere source of information, and the translator is assumed to be an expert who depending on the text type and function or purpose of the original text, decides what role the translated text is to play in the target language and culture.

- "Application of Lexical- Functional Theory in Designing an English Persian Translation Machine” by Farough Hendevalan J.A., Jahangiri N.(2008), which deals with sentences that are ambiguous for translation machine and the machine generates two constituent structures for them: i.e. distinguishing "phrasal verb + noun phrase" from "verb + prepositional phrase" and distinguishing "noun phrase + prepositional phrase" from "noun phrase" and "prepositional phrase". To disambiguate these sentences, the solution taken by a human translator, i.e. using semantic information, is modulated for machine through lexical mapping theory.

\section{METHODOLOGY}

The corpus-based approach is a useful tool to reduce subjectivity in evaluation translations when it comes to terms, expressions, collocations, and semantic prosody, but the rang of information that could be drawn from the corpus could be widened every further if the users' linguistic focus extended beyond the expression level to the systemic functional meaning-based level. 
This research is based on SFG approach that analyzes the translation errors of 15 participants as linguistic corpus selected randomly from among 400 persons who participated in the English-Persian translation exam held by the Iranian Judiciary for employing a number of official English translators. Most of the participants are translators at academic level or with a limited experience of living in an English-speaking country. They were given 3 hours to translate totally 735 English words in 4 separate texts with different legal subjects into Persian. They were allowed to use any kind of law dictionary, as well. For analyzing the collected data, first of all the researcher divided all texts into 112 sentences (including simple and compound sentences). Each sentence was then analyzed according to the three different metafunctions: ideational, interpersonal and textual. The ideational metafunction was further analyzed into two modes of meaning: experiential and logical. In order to understand experiential meaning, each sentence was broken down into three functional constituents: Participant, Process and Circumstance. For the analysis of interpersonal meaning, Subject and Finite relation were identified and for the analysis of thematic meaning, Theme and Rheme relations were identified. Each translation was subsequently checked by the researchers and problematic parts in terms of accuracy and appropriateness were underlined and marked with $\mathbf{E}$ for experiential meaning error, $\mathbf{L}$ for logical meaning error, I for interpersonal meaning error and $\mathbf{T}$ for textual meaning error, where possible. When all three transitivity constituents in a sentence, namely Participant, Process and Circumstance, were wrong, it was classified as a mistranslation; when a whole clause was not translated, it was classified as omission; and when the word-level equivalence was wrong, it was classified as word choice error. It should be noted that in this research spelling mistakes were ignored (Kim, 2010)

\section{DATA Analysis}

In this part some examples of translation errors in different metafunctions are discussed. For each example, the source text (ST) is accompanied by the target text (TT) and the back translation (BT) of the target text (i.e. translation of the translated text back into the language of the original text that here is English) as well as an alterative translation (AT). Also the problematic parts are highlighted in bold. Now in the following examples we will consider some of the translation errors with different metafunctions.

\section{Example 1:}

participant
ST: $\frac{\text { The official translators or the officers of the consulate }}{\text { shall certify }}$ the authenticity of
translations and the conformity of the copy with the original in all cases.

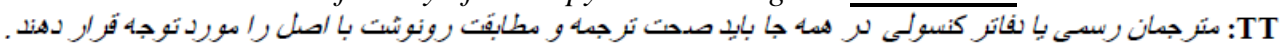

BT: The official translators or the consulate offices everywhere must consider the authenticity of translation and the conformity of the copy with the original.

In example (1), there are three experiential issues in the target text which are highlighted in bold. One is an error in participant "the officers of the consulate" which refers to the authorities of the consulate but the target text fails to convey the exact meaning and the expression "the consulate offices" refers to the place of the consulate not the authorities. The second issue is mistranslation of circumstance " in all cases" as "everywhere" in the target text. Further as the third issue, the main component of experience in source text, that is represented by the process "shall certify" is translated as "must consider" in which the modal verb "must" has much stronger necessity and force and the main verb is mistranslated; Therefore considering the above issues, the experiential metafunction is misrepresented in the target text. An alterative translation would be:

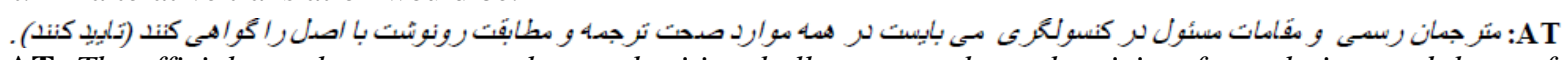

AT: The official translators or consulate authorities shall approve the authenticity of translation and the conformity of the copy with the original.

Example 2:

Word choice non-finite dependant clause

ST: Hearsay evidence will be admissible to be considered as primary evidence if the first

word choice

witness had died or is unable to be called owing to other impediments such as sickness, travel, imprisonment, etc.

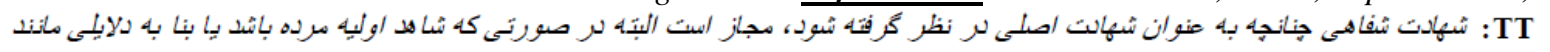

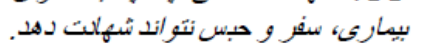

BT: If the oral evidence is considered as primary evidence, it is permitted; of course if the first witness has died or because of some reasons such as sickness, travel or imprisonment can not give evidence.

In this example there is a logical metafunction error. In the source text " to be considered as primary evidence" is a non-finite dependant clause which functions to provide the purpose for the previous clause. But in the target text, it is presented as a conditional clause " if the oral evidence is considered as primary evidence". Therefore the target text fails to convey the logical relations. Also, there are two errors in the word choice within the target text. The first is "hearsay evidence" that is translated as "oral evidence" and the other is "impediments" that is translated as "reasons". So an alternate translation would be: 


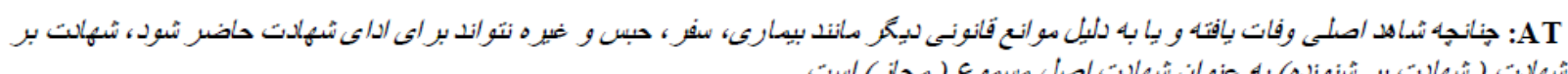

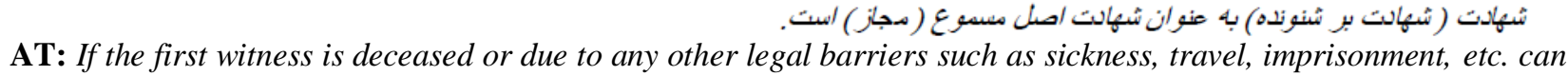
not give testimony, the second-hand evidence is admissible as a primary evidence.

Example 3:

Circumstance / textual theme / mistranslation

participant/topical them/mistranslation

ST: Not restricting the generality of functions referred to hereafter, the Broad of Directors

Process mistranslation

acts exclusively as the representative of the company before all judicial, governmental, rheme

omission

Non-governmental authorities, real persons and legal entities, whether Iranian or foreigner.

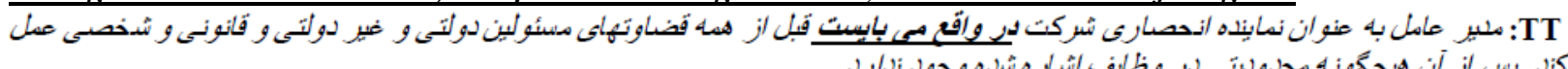

BT: Managing Director must actually act as exclusive representative of company prior to all judgments of governmental, non-governmental, real and legal authorities. After that there is no restriction in the said function.

In example (3), there is an error in textual metafunction. In the source text, the textual theme "not restricting the generality of functions referred to hereafter" is used to draw the reader's attention, but in the target text not only the textual effect of the source text is not efficiently created and the sentence begins with the topical theme" Managing Director" which is translated wrongly instead of "Board of Directors", but also that part of sentence is translated as a separate sentence with wrong meaning.

In addition, there is another mistranslation together with omission in the last part of the source text (i.e. from "before..." till the end of sentence). Therefore in translation of this example there are two experiential errors, one textual error, three cases of mistranslation and one case of omission. Further to the said errors, there is an error in interpersonal meaning too. It means that using the expression "must actually" in translation, adds an unnecessary force to the meaning of target text. An alternative translation would be:

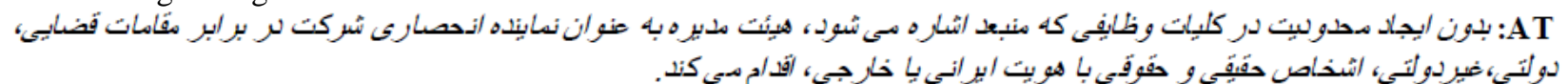

AT: Without any restriction in generality of the following duties that will be assigned, the board of directors acts as the exclusive representative of company before all judicial, governmental and non-governmental authorities as well as real persons and legal entities, with Iranian or foreign identities.

In general, table 1 indicates the number of translation errors of each person in the nine error categories. The last column shows the average number of sentences that contain each type of translation error.

TABLE 1

NUMBER OF ERRORS IN 9 ERROR CATEGORIES

\begin{tabular}{|l|l|l|l|l|l|l|l|l|l|l|l|l|l|l|l|l|l|}
\hline \multicolumn{1}{|c}{$\begin{array}{c}\text { Selected } \\
\text { Participant }\end{array}$} & $\mathbf{1}$ & $\mathbf{2}$ & $\mathbf{3}$ & $\mathbf{4}$ & $\mathbf{5}$ & $\mathbf{6}$ & $\mathbf{7}$ & $\mathbf{8}$ & $\mathbf{9}$ & $\mathbf{1 0}$ & $\mathbf{1 1}$ & $\mathbf{1 2}$ & $\mathbf{1 3}$ & $\mathbf{1 4}$ & $\mathbf{1 5}$ & Total & Average \\
Errors Types & & & & & & & & & & & & & & & & \\
\hline Interpersonal & 3 & & 2 & 1 & & 1 & & 2 & & 5 & 6 & 3 & & 2 & 2 & 27 & 1.8 \\
\hline Textual & 2 & & 7 & & & & & & 1 & 2 & 1 & 5 & 5 & & 3 & 26 & 1.73 \\
\hline Logical & & 2 & & & 5 & 1 & 4 & 2 & & & 3 & 1 & & 2 & & 20 & 1.33 \\
\hline $\begin{array}{l}\text { Experiential: } \\
\text {-Process }\end{array}$ & 5 & 6 & 4 & 2 & 2 & & 5 & 6 & & 8 & 2 & 1 & 1 & 3 & & 45 & 3 \\
-Participant \\
-Circumstance
\end{tabular}

One of the findings of this study is that individual participants may have certain pattern of errors, which reveals the areas in which they are weak and they need to improve. Fig. 1 shows the distribution of errors for participant 4 in comparison with participant 7.

Participant 4 is one of the two persons who has made the fewest errors (i.e. 7 errors) and participant 7 has made the middle errors (i.e. 19). As the graph in fig. 1 shows, participant 7 didn't make any errors in five categories: textual, logical, participant, mistranslation and omission. On the other hand participant 7 didn't make any errors in two categories: interpersonal and textual. This means that their linguistic sensitivity and competence in those areas where they did not make error is very high and reliable, at least in this text.

Further, participant 4 , has made one error in interpersonal and circumstance categories and two errors in process category. In terms of interpersonal, process, circumstance categories (i.e. experiential metafunction), the errors that participant 4 has made is roughly the same as the average, but he may need to give more attention to word choice in translation, as his three errors in the word choice category are more than the average of 2.53 in this linguistic corpus. 
Likewise considering the same graph, it is shown that participant 7 has made one error in circumstance and mistranslation categories and two errors in omission and word choice categories; and they do not seem to be major problems to be considered since the average number are between 1.13 to 2.53 respectively and these errors are less than the relevant average. In fact she should give more attention to expressing logical meaning, participant and process since her four errors in participant and logical categories and five errors in process category are more than the average which is $1.86,1.33 \& 3$ respectively.

High average figures in a particular category means either the source text presents difficulties in such categories or the group of participants in the translation exam is weak in those areas. In addition, the repetition of the same pattern of errors by a group of participant would be a good indicator for legal translators and teachers of areas requiring further practice and explanation.

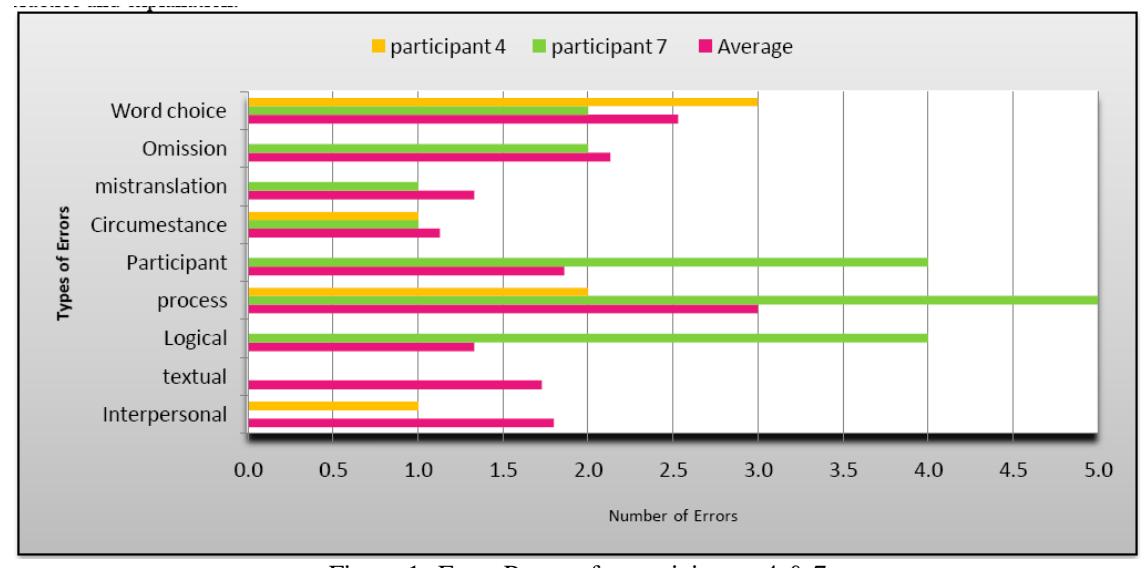

Figure 1- Error Pattern for participants 4 \& 7

\section{CONCLUSION}

Legal translators and translation students should be aware of the intention of the original text as well as the interpretation that has been attached to text. Errors in legal translation could be fatal due to the potential after- effect of a legal misjudgment which could affect the life and rights of individuals as well as the national security and diplomatic relations.

To avoid mistakes, legal translators need to understand the different law systems as well as specific areas within law such as criminal law, commercial law, property law, etc. Further they should be guided by standards of linguistic, social and cultural equivalence between language used in the source text and the target language. They also need to be competent in legal writing and have an in-depth knowledge of legal terminology. In general, most of the translation errors, specially in legal translation, are because of:

a) Neglecting the translation principles; b) Unawareness of the negative connotation meaning of some words in the target language, for example in English -Persian dictionaries, the word "notorious" is equal to "معروف" (famous) but it has a negative connotation meaning that is "well-known in bad things" and some translators use this word to express famous characteristics which results in mistranslation; c) Overgeneralization of some morphological rules, for example the suffix (-less) often adds a negative meaning to the stem word such as "careless" but in some cases as in the word "priceless" it means "valuable" (نفيس، ارزشمنا) not "without value" (بى ارزش).

Further to the above issues, analyzing the data shows that it is possible to classify errors in target text based on a meaning-based approach, i.e. SFG. In this research errors were identified at sentence level but it would be meaningful to investigate beyond it in follow-up studies. Most of the errors identified here were classified into different metafunctions as well as some other issues such as omission, mistranslation and word choice.

Findings of this research can be used by legal translators to translate legal documents accurately and by teachers to give systematic feedback on individual errors and to evaluate the students' translations objectively. For example, instead of saying that "you should not add or miss anything in translation", they can actually articulate when addition or mission might or might not be justifiable, and also provide explanations for this by referring to what meaning is changed .This meaning-based approach to translation can empower translators and students to think systematically about the translation options they have and articulate reasons for their choices. This is due to the fact that feedback on their translation errors is not based on one's subjective judgment but on systematic, linguistic knowledge, which serves as a basis for students to make informed translation decisions.

Using this classification, teachers can also give individual students systematic feedback on language competence, indicating their relatively weak and strong areas. One instance of translation might not be enough to detect areas of weakness but if repeated error patterns are observed that would be a good indicator.

Research attempts like this small study that address theoretical and/or practical gaps in translation studies can eventually enrich both translation studies and other relevant disciplines. It is worth mentioning that follow-up 
researches may be conducted to further investigate whether or not this translation error analysis based on SFG helps students develop translation skills and leads to improvement of translation quality. Also this approach may be implemented as an objective evaluating software that can analyze the translation of different texts automatically and in this way can save the human time and energy, consequently.

\section{REFERENCES}

[1] Baker, M. (1992). In Other Words. London/New York: Routledge.

[2] Cao, D. (2010). Legal Translation. In Coulthard M. \& A. Johnson. The Routledge Handbook of Forensic Linguistics. London \& USA: Routledge- pp. 78-91

[3] Faroughi Hendevalan, J.A. \& Jahangiri N. (2008). Application of Lexical-functional Theory in Designing an English- Persian Translation Machine. Translation Studies Journal. 6(21): 25-47 - Iran

[4] Halliday, M A. K. (1994). An Introduction to Functional Grammar (2nd edition). London/New York/Sydney/Auckland: Arnold.

[5] Hatim, B. \& I. Mason. (1990). Discourse and the Translator. London: Longman.

[6] Hatim, B. \& I. Mason. (1997).The Translator as Communicator. London/New York: Routledge.

[7] House, J. (1986). Acquiring Translational Competence in Interaction. In House J. \& Sh. Blum - Kulka (eds.) Interlingual and Intercultural Communication: Discourse and cognition in translation and second language acquisition studies (PP. 179 - 91). Tübingen: Narr.

[8] Khomeyjani Farahani, A. A. (2005). A Framework for Translation Evaluation. Translation Studies Journal. 3(9): 75-86 -Iran

[9] Kim, M. (2010) .Translation Error Analysis: A Systemic Functional Grammar Approach. In Coffin C., Th. Lillis \& K. O'Halloran (eds.). Applied Linguistics Methods A Reader London \& USA: Routledge- pp. 84-94

[10] Manafi Ansari, S. (2004). A Function- Based Approach to Translation Quality Assessment. Translation Studies Journal. 1(4): 31-52 - Iran.

[11] Matthiessen, Ch. M.L.M., K. Teruya \& M. Lam (2010). Key Terms In Systemic Functional Linguistics, London/New York: Continuum.

[12] Trosborg, A. (2002). Discourse Analysis as Part of Translator Training. In Ch. Schäffner (ed.). The Role of Discourse Analysis for Translation and in Translator Training: Status, need, methods. Clevedon: Multilingual Matters- pp. 9-52

[13] Vlachopoulos, S.(2004). Translating the Understandable? The Impact of cultural constraints on the Translation of Legal Text. In J.Gibbons, V. Pakasam, K.V. Tirumalesh \& H. Nagarajan (eds.), Language in the Law. Delhi: Orient Longman- pp 100-115.

[14] Williams, G. (1994) Using systemic Grammar in Teaching Young Learners: An introduction. Melbourne: Macmillan Education Australia.

Ferdows Aghagolzadeh is currently Associate Professor, Faculty Board Member \& Director of Linguistic Department at Tarbiat Modarres University, Tehran-Iran. He has been engaged in teaching linguistic courses; especially discourse analysis, pragmatics, as well as applied linguistics for many years. He holds Ph.D in General Linguistics, M.A in Linguistics and B.A in English Language and Literature. He has published a number of books and many articles in his area of interest in academic journals and he has conducted many research projects as well.

Faezeh Farazandeh-pour is Student of Doctorate Degree Program in the field of Linguistics at Tarbiat Modarres University and Official English Translator to the Iranian Judiciary. She holds M.A in Linguistics and B.A in English Language Translation and now she is engaged in preparing her doctoral thesis in Forensic Linguistics. She has conducted a number of research projects and published several articles in her area of interest, especially in forensic linguistics and applied linguistics. 